\title{
Application of interferometry to studies of glacier dynamics
}

\author{
Mohr, Johan Jacob; Madsen, Søren Nørvang
}

Published in:

Geoscience and Remote Sensing Symposium, 1996. IGARSS '96

Link to article, DOI:

10.1109/IGARSS.1996.516538

Publication date:

1996

Document Version

Publisher's PDF, also known as Version of record

Link back to DTU Orbit

Citation (APA):

Mohr, J. J., \& Madsen, S. N. (1996). Application of interferometry to studies of glacier dynamics. In Geoscience and Remote Sensing Symposium, 1996. IGARSS '96: 'Remote Sensing for a Sustainable Future.', International (Vol. 2, pp. 972-974). IEEE. https://doi.org/10.1109/IGARSS.1996.516538

\section{General rights}

Copyright and moral rights for the publications made accessible in the public portal are retained by the authors and/or other copyright owners and it is a condition of accessing publications that users recognise and abide by the legal requirements associated with these rights.

- Users may download and print one copy of any publication from the public portal for the purpose of private study or research.

- You may not further distribute the material or use it for any profit-making activity or commercial gain

- You may freely distribute the URL identifying the publication in the public portal

If you believe that this document breaches copyright please contact us providing details, and we will remove access to the work immediately and investigate your claim. 


\title{
Application of Interferometry to Studies of Glacier Dynamics
}

\author{
Johan Jacob Mohr, Søren Nørvang Madsen \\ Danish Center for Remote Sensing, Dept. of Electromagnetic Systems \\ Technical University of Denmark, B-348, DK-2800 Lyngby, Denmark \\ Phone: +45 4525 3800, Fax: +45 4593 1634, Email: jm@emi.dtu.dk
}

\begin{abstract}
Multi baseline repeat track interferometry (RTI) can potentially be used to measure both velocities and the micro topography of glaciers. The Danish Center for Remote Sensing ${ }^{\dagger}$ (DCRS) in corporation with the Danish Polar Center (DPC) has established a test cite for studies of glacier dynamics on the Storstrømmen glacier in North East Greenland. DCRS has acquired RTI data over the glacier in 1994 and 1995 and ERS-1/2 tandem mode data are also available. This paper presents recent results from this study. The advantages of satellite and airborne RTI respectively is described. The paper concludes with an analysis of different configurations of the spatial and temporal baselines.
\end{abstract}

\section{INTRODUCTION}

The ice sheets of Greenland and Antarctica are important components in the global climate system. Glaciers might act as indicators of changes in the ice sheet, thus monitoring methods are of significant interest. A joint project between the Danish Center for Remote Sensing (DCRS) and the Danish Polar Center (DPC) addresses the utility of airborne as well as satellite repeat track interferometry (RTI) for studies of glacier dynamics particularly as it relates to mass balance estimation.

Repeat track interferometry can provide measurements of surface displacements at sub-centimeter levels and/or relative topography with decimeters accuracy. However, the successful combination of two or more aircraft images to interferograms requires control of the trajectory to within a few meters. In the repeat pass mode the aircraft carrying EMISAR ${ }^{\dagger \dagger}$ is controlled by the radar control computer via the Instrument Landing System (ILS) which again receives its navigational information from a P-code GPS receiver, thus allowing routine acquisitions of RTI data.

For the interpretation of the interferograms the required accuracy is even more stringent, since all errors in the

† The Danish Center for Remote Sensing (DCRS) is established and funded by the Danish National Research Foundation.

tit Development of the EMISAR was sponsored by the Thomas B. Thriges Foundation, the Danish Technical Research Counsil (STVF), the Royal Danish Air Force (RDAF), the Technical University of Denmark and the Joint Research Centre (JRC). knowledge of the spatial baseline directly translate into the same errors in the displacement measurements. This is essential, due to the small temporal baselines achievable in airborne interferometry. When a spatial baseline is present the topography as well contributes to the interferogram phase, but with the application of multi-baseline techniques this component can, in principle, be removed.

\section{EXPERIMENTS ON STORSTRØMMEN}

The two DCRS studies investigating the utility of repeat track interferometry for studies of glacier dynamics uses airborne EMISAR data and data from the ERS-1/2 satellites respectively. For both studies Storstrømmen is selected as the primary test area.

The airborne EMISAR experiments are conducted in a $10 \mathrm{~km}$ $(N-S)$ by $30 \mathrm{~km}$ (E-W) area in the lower part of Storstrømmen. In 1994 DPC deployed four corner reflectors on solid rock in the test area and surveyed their positions by GPS. In 1995 the four reflectors were checked and their position resurveyed.

The reflectors serve as reference points for the RTI data. In august 1994 the area was covered by C-band RTI data acquisitions on a one day mission. In august $1995 \mathrm{~L}$-band data were acquired on two consecutive days, thus giving a one day temporal baseline - an order of magnitude greater than for the 1994 data.

Airborne interferograms from 1994 as well as 1995 shows very low phase noise and are easily unwrapped.

The spatial baselines, extracted from the combination of GPS and the radar Inertial Navigation Unit (INU), have been refined with a parametric error model tuned with co-registration errors from numerous small image patches, [1]. The uncertainties on the baseline estimates, though reduced from several meters to the centimeter level, are still not sufficiently accurate to be used for an extraction of the glacial velocity know to be on the order of meters per year. The major unknown, is probably a very low frequency INU drift which is presently being studied.

The satellite project concerns data from the European Space Agency (ESA) ERS-1 (launched June, 1991) and ERS-2 (launched April , 1995) sensors. The satellites are presently operated in a tandem mode such that, seen from the earth, ERS-2 repeats the ERS-1 trajectory with a one day delay. The satellites are in a 35 day repeat cycle, thus allowing the 
generation of one interferogram with a one day temporal baseline every 35 day for any area.

After correcting the ERS data for missing lines and digitization window changes we generated single look complex images, estimated baselines, and formed interferograms. On Fig. 1 a raw interferogram covering a $100 \mathrm{~km}$ by $200 \mathrm{~km}$ area around Storstrommen is shown. On the left the interferogram phase is shown, on the right the amplitude. The phase is color coded and is repeated for each $2 \pi$, in this case corresponding to either a change in the terrain height of $800 \mathrm{~m}$ or a line of sight motion of $2.8 \mathrm{~cm} /$ day. Two interferograms with a 35 day separation have presently been generated. However, one of the interferograms is rather difficult to phase unwrap, likely due to temporal decorrelation thus resulting in a low correlation interferogram.

Manually counting the fringes on the mountains shows that a minor tilt of 1-2 fringes is still present. It is also noted that the topography in this area can account for at most 2 fringes. Thus the fringe pattern on the upper part of the glacier (with an eastward flow) must be due to a horizontal surface velocity of approximately $300 \mathrm{~m} / \mathrm{y}$ in the central part decreasing to approximately zero at the sides. The almost vanishing fringe pattern on the lower part (with a southward flow) can not easily be interpreted as only the line of sight component of the motion can be determined, thus providing virtually no sensitivity to velocity measurement in this flow direction.

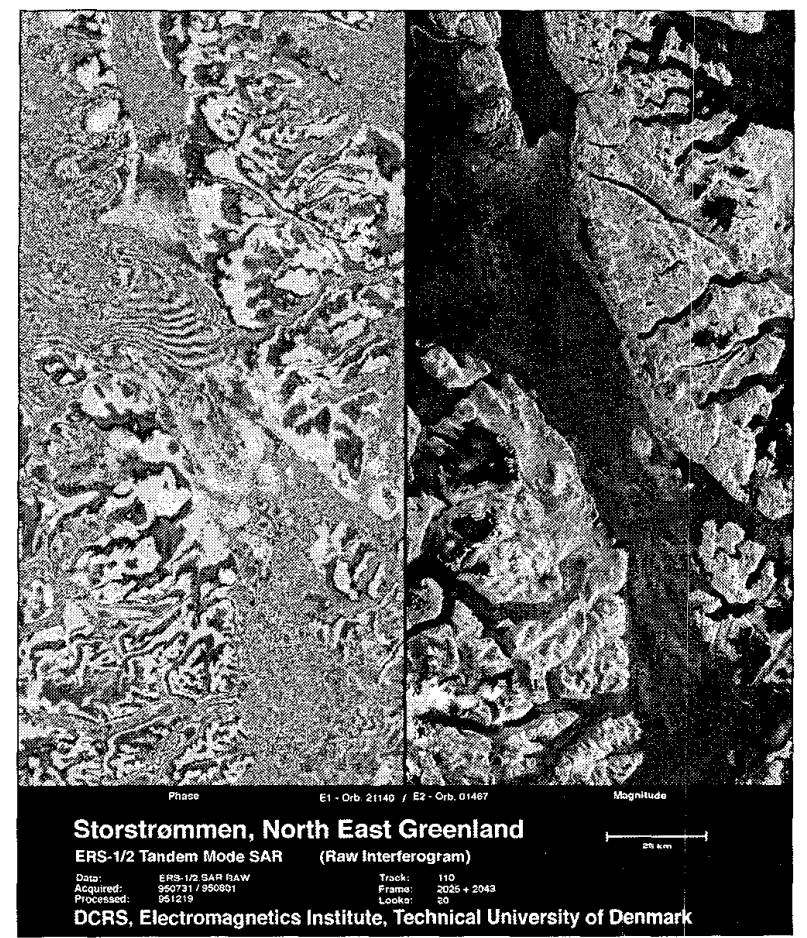

Fig 1. Raw interferogram from ERS-1/2 tandem data.

\section{AIRBORNE VS. SATELLITE INTERFEROMETRY}

From a users point of view the most significant advantages and disadvantages of airborne vs. satellite interferometry are:

- Coverage and resolution. Satellite images have large coverage and coarse resolution. Data amounts as well as acquisition time limits the coverage of an airborne sensor. One airborne data file of the $10 \mathrm{~km}$ times $30 \mathrm{~km}$ test fields has approximately the same size (1 Gbyte) as a full $100 \mathrm{~km}$ times $200 \mathrm{~km}$ ERS image.

- Spatial availability. Areas coverage for a satellite is inflexible since the satellite tracks are predetermined, as opposed to airborne interferometry. On the other hand, satellites does obtain global coverage in just a few days.

- Temporal availability. The satellite data generally have a fixed temporal baseline. The spatial baseline for an airborne system can in principle be chosen freely, but of course cost issues are of major importance

- Velocity modeling. Again since the satellite tracks are predetermined only one velocity component can be measured (two, if ascending and descending orbits are combined). In the ERS case the angle between the tracks is small $\left(20^{\circ}-30^{\circ}\right)$ and ascending tracks are unfortunately not acquired at the moment. With airborne interferometry images can be acquired from different angles, in principle enabling the measurement of the 2-D (or even the 3-D) velocity pattern.

- Viewing geometry. Satellites usually uses steep incidence angles inhibiting mapping of rough terrain.

From an engineering point of view airborne data are usually easy to unwrap as opposed to satellite data. On the other hand baseline estimation is much more difficult for airborne systems.

\section{SENSITIVITY ANALYSIS}

The application of RTI to studies of glacier dynamics, has the inherent problem that topography as well as glacial movement contributes to the interferogram phase. The phase of a pixel, $\varphi_{i j}$, in an interferogram formed from two images denoted $i$ and $j$, see Fig. 2, are (to first order)

$$
\varphi_{i j}=-\frac{4 \pi}{\lambda}\left(B_{\|, i j}+B_{\perp, i j} \Delta \theta-\Delta \rho_{i j}\right)+\varepsilon_{i j} .
$$

In (1) $\lambda$ denotes the wavelength, $B_{11, i j}$ and $B_{\perp, i j}$ the parallel and perpendicular baselines (assuming a flat earth), $\Delta \theta$ the angular deviation from the reference surface, $\Delta \rho_{i j}$ the line of sight (LOS) motion of the scene in the pixel and $\varepsilon_{i j}$ the phase noise, [2]. Note that motion compensation to a common reference line or the removal of the flat earth phase are two alternative means to remove the parallel baseline component before the interferogram is interpreted. It is obvious that topography and displacement can not be determined unambiguously from (1). The ambiguity can be solved in one of the following ways: 


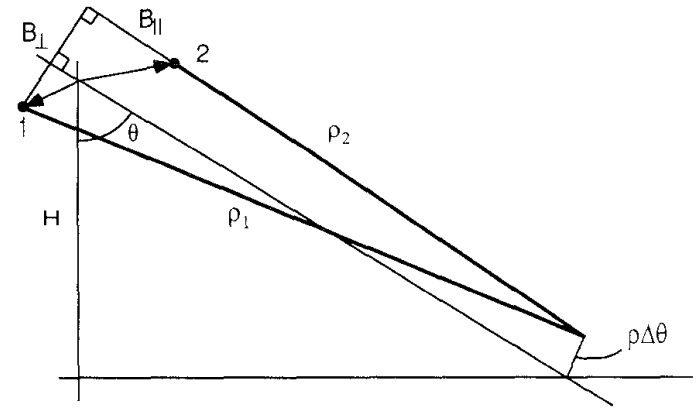

Fig. 2. Geometry for interferometric pair.

I. The topography term, $\Delta \theta$, can be supplied from another source, - a digital elevation model (DEM), [3].

II. Multiple interferograms can be utilized. If the flow field is stationary the displacements $\Delta \rho_{i j}$ can be collapsed into one unknown velocity $v$, since the temporal baseline are usually well known, [4].

III. The spatial baseline can be chosen to (or by change be) zero, such that the sensitivity to topography is zero, [5].

Though III is simplest, it is usually difficult to acquire such data and one must rely on either I or II. The following will focus on II as DEM's of Arctic regions are not widely available.

With a multi baseline technique (option II) the height and velocity of each pixel in the interferogram is 'optimally' found by solving a set of linear equations similar to (1) in a least square sense. To analyze the sensitivity of the solution, the equations corresponding to two interferograms, denoted 12 and 23 , are investigated. To simplify the analysis the perpendicular spatial baselines and the temporal baselines are written as

$$
\begin{aligned}
& B_{\perp, 12}=B \sin \alpha, \quad B_{\perp, 23}=B \cos \alpha, \quad \alpha \in[-\pi / 2 ;+\pi / 2] \\
& T_{12}=t T, \quad T_{23}=(1-t) T, \quad t \in[0 ; 1]
\end{aligned}
$$

If $\delta_{\|}$denotes the standard deviation of the parallel baseline estimates (assumed common for all $(i, j)$ ) and $\delta_{1}$ the perpendicular baseline, it can be shown that the uncertainties on the topography, $\Delta \vec{\theta}$, and velocity, $\vec{\nu}$, estimates are

$$
\begin{aligned}
& \delta_{\Delta \tilde{\theta}}^{2}=\frac{1}{B^{2}} \frac{t^{2}+(1-t)^{2}}{((1-t) \sin \alpha-t \cos \alpha)^{2}}\left(\delta_{\|}^{2}+\Delta \theta \delta_{\perp}^{2}\right) \\
& \delta_{\tilde{v}}^{2}=\frac{1}{T^{2}} \frac{1}{((1-t) \sin \alpha-t \cos \alpha)^{2}}\left(\delta_{\|}^{2}+\Delta \theta \delta_{\perp}^{2}\right)
\end{aligned}
$$

It turns out that the uncertainty due to phase noise with a variance denoted $\sigma_{\varepsilon}^{2}$ can be calculated from (2)-(3) as well, by substituting $(\lambda / 4 \pi)^{2} \sigma_{\varepsilon}^{2}$ for $\left(\delta_{\|}^{2}+\Delta \theta \delta_{\perp}^{2}\right)$.

The most significant conclusion is that the topography uncertainty is independent of the total time span, $T$, and is ninimized by choosing a configuration with large spatial baselines, $B$. Reversely the velocity uncertainties is independent of the magnitude of $B$ and minimized by choosing a large $T$. This is of course only valid to a certain extend, since other issues such as temporal decorrelation, geometrical decorrelation and phase unwrapping must be taken into account

If the temporal baselines can be chosen freely the global minimas are reached when $(t, \alpha)$ are chosen such that one interferogram has a zero temporal baseline and a large spatial baseline and the other conversely has a large spatial and a zero temporal baseline.

When the temporal baselines can not be chosen freely, the optimal spatial baseline ratio is easily found from (2) or (3). An interesting special case is the ERS-1/2 tandem mode data where $t=0.5$. In that case the optimal spatial baselines for a velocity estimation has same magnitude but opposite sign. Note that as long as the baselines have opposite sign the standard deviation is at most a factor of $\sqrt{2}$ larger than the optimal.

\section{CONCLUSION}

Raw data from the ERS-1/2 satellites have been processed and the spatial baselines are estimated to within $10 \mathrm{~cm}$. Precision orbit data with a similar accuracy, now available from ESA, might be used in the future. Manual fringe counting on the upper part of Storstrømmen shows horizontal surface velocities of approximately $300 \mathrm{~m} / \mathrm{y}$ in the central part decreasing to approximately zero at the sides, in good agreement with in-situ measurements. The interferograms, though, need to be augmented with airborne data, since the flow of the lower part of the glacier is almost perpendicular to the ERS line of sight. Airborne data unwraps well. The uncertainty on the spatial baselines has been reduced from several meters to the centimeter level, but since the residual errors are not linear but rather caused by a small drift in the INU, this is not sufficiently accurate. Work on the estimation of such a non-linear baseline uncertainty is in progress.

\section{REFERENCES}

[1] Johan J. Mohr and Søren N. Madsen, "Parametric Estimation of Time Varying Baselines in Airborne Interferometric SAR," these proceedings.

[2] Søren N. Madsen and Howard Zebker, "Imaging Radar Interferometry," chapter 17 in Manual of Remote Sensing, Vol III, 1996, in press.

[3] D. Massonnet et al., "The displacement field of the Landers earthquake mapped by radar interferometry," Nature, Vol. 364, July 8. 1993, pp. 138-142.

[4] R. Kwok and M.A. Fahnestock, "Ice Sheet Motion and Topography from Radar Interferometry," IEEE trans. Geosci. Remote Sensing, Vol. 34, No. 1, Jan. 1996 , pp. 189-200.

[5] R.M. Goldstein, H. Engelhardt, B. Kamb and R.M. Frolich, "Satellite Radar Interferometry for Monitoring Ice Sheet Motion: Application to an Arctic Ice Stream," Science, Vol. 262, pp. 1282-1285. 